\title{
Cost-effectiveness of the Australian National Tobacco Campaign
}

\author{
S F Hurley and J P Matthews
}

Tob. Control 2008;17;379-384; originally published online 21 Aug 2008; doi:10.1136/tc.2008.025213

Updated information and services can be found at:

http://tobaccocontrol.bmj.com/cgi/content/full/17/6/379

References This article cites 30 articles, 17 of which can be accessed free at:

http://tobaccocontrol.bmj.com/cgi/content/full/17/6/379\#BIBL

Rapid responses You can respond to this article at:

http://tobaccocontrol.bmj.com/cgi/eletter-submit/17/6/379

Email alerting Receive free email alerts when new articles cite this article - sign up in the box at service the top right corner of the article

Topic collections Articles on similar topics can be found in the following collections

Smoking (2509 articles)

Smoking cessation (11 articles)

Health effects of tobacco use (10 articles)

Tobacco use (52 articles)

\section{Notes}

To order reprints of this article go to:

http://journals.bmj.com/cgi/reprintform

To subscribe to Tobacco Control go to:

http://journals.bmj.com/subscriptions/ 


\title{
Cost-effectiveness of the Australian National Tobacco Campaign
}

\author{
S F Hurley, ${ }^{1,2,3}$ J P Matthews ${ }^{1}$
}

${ }^{1}$ Bainbridge Consultants Pty Ltd, Melbourne, Australia; ${ }^{2}$ School of Medicine, Griffith University, Australia; ${ }^{3}$ School of Population Health, The University of Melbourne, Australia

Correspondence to: Professor Susan Hurley, Bainbridge Consultants Pty Ltd, 222/299 Queen Street,

Melbourne, VIC 3000, Australia; susanhurley@

bainbridgeconsultants.com

Received 24 February 2008 Accepted 7 August 2008

Published Online First

21 August 2008

\section{ABSTRACT}

Background: The Australian National Tobacco Campaign (NTC) was an intensive mass media anti-smoking campaign, the first phase of which commenced in 1997, cost around \$A9 million, and reduced smoking prevalence by $1.4 \%$.

Objective: To assess the cost-effectiveness of phase one of the NTC, which ran from June to November 1997.

Design and study population: The quit benefits model (QBM), a Markov-cycle simulation model was used to predict the benefits of smoking cessation for the estimated 190000 quitters from the time of quitting until death, censored at age 85 years. Measures of effectiveness were cases of lung cancer, acute myocardial infarction (AMI), stroke and chronic obstructive pulmonary disease (COPD) avoided; deaths prevented, and life-years and quality-adjusted life-years (QALYs) gained. The savings in healthcare costs through prevention of the four specified smoking-associated diseases were estimated. Future costs, life-years and QALYS were discounted at 3\% per year.

Results: The QBM predicted that the NTC avoided over 32000 cases of COPD, 11000 cases of AMI, 10000 cases of lung cancer, and 2500 cases of stroke. Prevention of around 55000 deaths, gains of 323000 life-years and 407000 OALYS, and healthcare cost savings of $\$ A 740.6$ million were predicted. The NTC was therefore both cost saving and effective.

Conclusions: As well as reducing smoking prevalence, the NTC was unequivocally cost-effective.

The Australian National Tobacco Campaign (NTC) was initiated by the federal government in June 1997, in response to an apparent stalling of the steady decline in the prevalence of smoking that had occurred in the 1980s and early 1990s. ${ }^{1}$ The NTC was the first substantive, sustained, coordinated tobacco control campaign implemented in all states and territories of Australia, ${ }^{2}$ and had distinctive features. It involved intensive broadcasting of new anti-smoking advertisements on television, and, in conjunction, the state and territory governments and their partner organisations increased funding for a range of support services, especially telephone quitlines for smokers who were attempting to quit. ${ }^{12}$

The NTC was a paradigm shift in terms of its confrontational anti-smoking messages, with graphic images of harm reflecting the campaign's slogan "every cigarette is doing you harm." In the first phase of the campaign between June and November 1997, three advertisements, "Artery", "Lung" and "Tumour", were introduced. The "Artery" advertisement, for example, depicts a plug of atherosclerotic deposit being squeezed from a disembodied aorta. In 1998, two additional advertisements were introduced, "Brain", showing a damaged brain oozing tissue and blood, and "Call for help", which showed a male smoker contacting the quitline and receiving praise and encouragement from a counsellor. The advertisements "Tar", showing tar being poured onto the cut surface of a lung, and "Eye", showing evolving damage to the retina as a capillary bursts, were introduced in 2000. ${ }^{13}$ These seven advertisements can be viewed at http://www. quitnow.info.au under "Smokescreen".

The initiation of the NTC involved a large increase in the Australian federal government budget for tobacco control measures, and it therefore commissioned numerous evaluation studies over the period 1997 to 2000, which have been published in three volumes. ${ }^{3-5}$ Although the NTC is an ongoing programme, it has been much less intensive since 2000. Television advertising has been sporadic and no new advertisements have been introduced. Phase one, between June and November 1997, was the most intensive phase of the NTC. Average monthly media spend was over \$A900 000 per month, compared with approximately $\$ A 400000$ to $\$ A 500000$ per month for subsequent phases. $^{3}$ An economic evaluation of phase one by Carter and Scollo predicted that the campaign would prevent 920 premature deaths, achieve 3338 additional years of life before age 75 , and yield savings of \$A24.2 million in the cost of treatment for lung cancer, chronic obstructive pulmonary disease (COPD) and cardiovascular disease. ${ }^{6}$ However, Carter and Scollo's analysis considered only one hypothetical future year in the lives of the cohort of quitters. The goal of this project was therefore to assess the cost-effectiveness of phase one of the NTC in a more comprehensive manner.

\section{METHODS}

\section{The benefits of quitting}

We used the Quit Benefits Model (OBM) to estimate the health benefits and healthcare cost savings of quitting for males and females in each five-year age group from 15-19 years for the remainder of their lifetime, censored at age 85 years. The OBM, which has been described in detail previously, ${ }^{7}$ is a Markov-cycle tree model, programmed in the software package TreeAge Pro. ${ }^{8}$ In the model, subjects were at risk each year of dying, or developing one of the four most common smoking-associated diseases-lung cancer, acute myocardial infarction (AMI), stroke or COPD Once a subject developed one of these conditions, disease progression was characterised by a series of annual transitions between health states defined 
by the number of years since diagnosis of the particular disease.

The OBM assumed that the risks of these four diseases were greater for smokers than for non-smokers and that risks declined over time for quitters. However, the risk of death due to the disease was independent of smoking or quitting status. The $\mathrm{OBM}$ also assumed that the risk of death from causes other than the four specified smoking-associated diseases was greater for smokers than for the general population and that, for quitters, this excess risk declined over time.

The sources of parameter estimates for the OBM are summarised in table 1 and have been described in more detail previously. The most recent year for which key data were available was 2001, and costs are quoted in 2001 Australian dollars. The disease incidence and mortality parameter estimates were all based on Australian data. The declines after quitting in risks of smoking-associated diseases, and mortality from causes other than these four diseases, were estimated from functions described previously, all of which were based on large international datasets. ${ }^{7}$ Cost estimates were based on Australian data, with the exception of COPD costs, which were sourced from a Canadian study. ${ }^{9}$ Utility estimates for stroke came from a meta-regression, ${ }^{10}$ and from an international registry for the other three diseases. ${ }^{11}$

The following outcomes were assessed: the probabilities of developing each of the four smoking associated diseases, the probabilities of dying from each of these diseases or other causes, total healthcare costs and costs for each disease, life expectancy and expected quality-adjusted life-years (OALYs). For each five-year age group, for males and females separately, the course of a hypothetical smoker was simulated, first assuming that the subject continued to smoke, and then assuming he or she quit. Expected values for costs, OALYs and life-years were estimated directly from Markov cohort analyses, and were discounted at $3 \%$ per year. ${ }^{12}$ To estimate the probabilities of disease and death (and hence numbers of cases of disease and deaths avoided) it was necessary to programme "tracker variables" in TreeAge and analyse the model using Monte Carlo simulation, which is substantially more computationally intensive and time consuming than a Markov cohort expected value analysis. ${ }^{13}$ Simulations were run for 10000

Table 1 Sources of data for model parameter estimates

\begin{tabular}{|c|c|}
\hline Parameter & Source \\
\hline \multicolumn{2}{|l|}{ Lung cancer } \\
\hline \multicolumn{2}{|l|}{ Incidence probability } \\
\hline Smokers & $\begin{array}{l}\text { Australian national incidence data for } 2001 \text { from the National Cancer Statistics Clearing House, }{ }^{34} \\
\text { adjusted on the basis of the RR of lung cancer for smokers versus never-smokers, }{ }^{35} \text { and the } \\
\text { estimated historical prevalence that gave rise to the current lung cancer epidemiology. }{ }^{75}\end{array}$ \\
\hline Quitters & Smokers' probabilities reduced over time after quitting according to an exponential model. ${ }^{7}$ \\
\hline Probability of death & Victorian Cancer Registry data for 1994-9. \\
\hline Utility of life & $\begin{array}{l}\text { The mean of two estimates from the Harvard Catalogue of preference scores, }{ }^{11} \text { and } 2 \text { more recent } \\
\text { studies. }^{3637}\end{array}$ \\
\hline Healthcare costs & Estimated from an Australian study, ${ }^{38}$ and a more recent study from the United Kingdom. ${ }^{79}$ \\
\hline \multicolumn{2}{|l|}{ AMI } \\
\hline \multicolumn{2}{|l|}{ Incidence probability } \\
\hline Smokers & $\begin{array}{l}\text { Population incidence estimated from Australian national mortality and hospitalisation data for } \\
2001,{ }^{40}{ }^{41} \text { then adjusted on the basis of the RR of AMI for smokers versus never-smokers, }{ }^{42} \text { and the } \\
\text { prevalence of smoking in } 2001 . .^{73}\end{array}$ \\
\hline Quitters & Smokers' probabilities reduced over time after quitting according to an exponential model. ${ }^{728}$ \\
\hline Probability of death & Estimated from population mortality rates, ${ }^{40}$ and incidence probabilities (above) using DisMod II. ${ }^{74}$ \\
\hline Utility of life & The mean of seven estimates from the Harvard Catalogue of preference scores. ${ }^{711}$ \\
\hline Healthcare costs & $\begin{array}{l}\text { Estimated from hospitalisation costs, }{ }^{28} \text { and assumptions about medications and ambulatory care } \\
\text { post-discharge. }\end{array}$ \\
\hline \multicolumn{2}{|l|}{ Stroke } \\
\hline \multicolumn{2}{|l|}{ Incidence probability } \\
\hline Smokers & $\begin{array}{l}\text { NEMESIS, an Australian population-based study of stroke incidence, }{ }^{45} \text { adjusted on the basis of the } \\
\text { RR of stroke for smokers versus never-smokers, }{ }^{42} \text { and the prevalence of smoking in } 2001 . .^{73}\end{array}$ \\
\hline Quitters & Smokers' probabilities reduced over time after quitting according to an exponential model. ${ }^{728}$ \\
\hline Probability of death & Perth Community Stroke Study. ${ }^{76} 47$ \\
\hline Utility of life & A meta-regression of 20 articles. $^{710}$ \\
\hline Healthcare costs & NEMESIS, an Australian population-based study of stroke, ${ }^{48}$ adjusted to 2001 dollars. ${ }^{715}$ \\
\hline \multicolumn{2}{|r|}{ 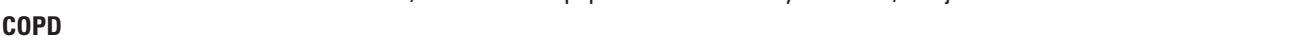 } \\
\hline \multicolumn{2}{|l|}{ Incidence probability } \\
\hline Smokers & $\begin{array}{l}\text { Australian incidence for } 2001 \text { estimated from COPD prevalence data using DisMod } I_{1}{ }^{7} \text { then adjusted } \\
\text { on the basis of the RR of COPD for smokers versus never-smokers, }{ }^{42} \text { and the estimated historical } \\
\text { prevalence of smoking, as for lung cancer. }{ }^{735}\end{array}$ \\
\hline Quitters & Smokers' probabilities reduced over time after quitting according to an exponential model. ${ }^{7}$ \\
\hline Probability of death & Estimated from population mortality rates, ${ }^{40}$ and incidence probabilities using DisMod II. ${ }^{74}$ \\
\hline Utility of life & The mean of three estimates from the Harvard Catalogue of preference scores. ${ }^{711}$ \\
\hline Healthcare costs & $\begin{array}{l}\text { The Canadian Confronting COPD study, }{ }^{9} \text { adjusted to Australian dollars on the basis of Purchasing } \\
\text { Power Parities. }{ }^{49}\end{array}$ \\
\hline \multicolumn{2}{|c|}{ Probability of death from other causes } \\
\hline Smokers & $\begin{array}{l}\text { Australian mortality data, }{ }^{40} \text { adjusted on the basis of the RR of mortality for smokers, }{ }^{50} \text { and the } \\
\text { prevalence of smoking in } 2001.7^{73}\end{array}$ \\
\hline Quitters & Smokers' probabilities reduced over time after quitting according to an exponential model. ${ }^{7}$ \\
\hline
\end{tabular}


Table 2 Predicted cases of disease and deaths avoided, and predicted healthcare costs saved, through the NTC*

\begin{tabular}{|c|c|c|c|}
\hline & \multirow{2}{*}{$\begin{array}{l}\text { Cases of disease avoided } \\
\text { Cases }(95 \% \mathrm{CI})\end{array}$} & \multirow{2}{*}{$\begin{array}{l}\text { Deaths avoided } \\
\text { Deaths }(95 \% \mathrm{CI})\end{array}$} & \multirow{2}{*}{$\begin{array}{l}\text { Healthcare costs } \\
\text { saved } \dagger\end{array}$} \\
\hline & & & \\
\hline Lung cancer & 10134 (9815 to 10454$)$ & 9872 (9556 to 10187$)$ & $\$ 163.24$ million \\
\hline AMI & 11498 (11032 to 11964$)$ & 11834 (11 416 to 12251$)$ & $\$ 110.77$ million \\
\hline Stroke & 2538 (2067 to 3009 ) & 4087 (3666 to 4509 ) & $\$ 91.85$ million \\
\hline COPD & 32682 (32 144 to 33219 ) & 26258 (25 793 to 26722$)$ & $\$ 374.71$ million \\
\hline $\begin{array}{l}\text { Any of the above four } \\
\text { diseases }\end{array}$ & 56852 (56 154 to 57531$)$ & 52050 (51392 to 52709$)$ & $\$ 740.57$ million \\
\hline $\begin{array}{l}\text { Causes other than the } \\
\text { above four diseases }\end{array}$ & & 2822 (2181 to 3463 ) & Not considered \\
\hline Total & & 54873 (54 224 to 55521$)$ & $\$ 740.57$ million \\
\hline
\end{tabular}

*For the remaining lifetime of the 190000 quitters, censored at age 85 years.

†Costs have been rounded; future costs discounted at $3 \%$ per annum.

$\mathrm{AMI}$, acute myocardial infarction; COPD, chronic obstructive pulmonary disease.

subjects in each age group/sex category. Summary results have generally been rounded to the nearest thousand.

\section{The benefits of the NTC}

As part of the NTC evaluation, household telephone surveys that enabled estimation of the number of quitters attributable of the NTC were conducted by the Roy Morgan Research Centre in May and November 1997. These surveys have been described in detail by Wakefield et al in volume one of the evaluation report. ${ }^{14}$ Briefly, around 2000 Australians aged 18 and over were interviewed in May 1997, and another sample of around 4200 were interviewed in November 1997. From the survey data, Wakefield and colleagues estimated that the prevalence of smoking in Australia dropped from $23.5 \%$ in May, to $22.1 \%$ in November, a fall of $1.4 \%$, after adjustment for age, sex and socioeconomic status. ${ }^{14}$ Carter and Scollo extrapolated the survey data to the Australian population distribution to estimate the number of Australians who quit smoking in response to the NTC, and their age group and sex distribution. ${ }^{6}$ In our analysis, we used Carter and Scollo's estimate of 190000 quitters aged between 15 and 64 years. Note that although the NTC was specifically designed to encourage smokers to quit, it may also have discouraged young people from taking up smoking. The reduction in prevalence is essentially a combined measure of the impact on quitting and uptake.

We estimated the benefit of the NTC for each outcome, by multiplying the number of quitters in each age group, for males and females separately, by the predicted benefit of quitting for individuals in that age group/sex category estimated from the $\mathrm{OBM}$, and summing across all age group/sex categories.

\section{The cost and cost-effectiveness of the NTC}

Carter and Scollo estimated that the NTC cost \$A8.95 million (in 1997 Australian dollars), comprising \$A7.1 million of federal expenditure, and $\$ 1.85$ million of additional expenditure by state and territory organisations. ${ }^{6}$ We adjusted this cost to 2001 dollars on the basis of the consumer price index, ${ }^{15}$ to give an estimate of \$10.1 million for the cost of the NTC.

The cost-effectiveness of the NTC was calculated in terms of the net cost per life-year saved and the net cost per OALY gained. The net cost was the cost of the campaign minus total healthcare cost savings attributable to quitting.

The healthcare cost savings associated with the NTC, discounted at $3 \%$ per annum, were also estimated at time horizons of 1, 2, 10 and 20 years after the commencement of the programme. These healthcare cost savings were compared with the cost of the NTC to determine the analytical time horizon at which the NTC became cost saving. To allow for the possibility that not all the reduction in smoking was due to the NTC, a sensitivity analysis was conducted assuming that only half the reduction in smoking prevalence was due to the NTC.

\section{RESULTS}

Table 2 summarises the predicted benefits of phase one of the NTC in terms of cases of disease and deaths avoided, and healthcare costs saved, over the remaining lifetime up to the age of 85 of the 190000 quitters. The 95\% confidence intervals indicate the variability in the estimates due to the simulation process, and not any other potential sources of variability in parameter estimates. We predicted that the NTC resulted in over 32000 fewer cases of COPD, over 11000 fewer cases of AMI, about 10000 fewer cases of lung cancer and about 2500 fewer cases of stroke. Approximately 52000 fewer deaths from these four diseases, and 55000 fewer total deaths were predicted as a consequence of quitting. Total healthcare costs savings were predicted to be around $\$ 740.6$ million (discounted at $3 \%$ per year), half of which was due to savings in the costs of COPD. The net cost of the NTC was therefore a predicted saving of $\$ 730.5$ million.

Our model predicted that the NTC resulted in 323000 more life-years and 407000 more OALYs for the 190000 quitters. The NTC was therefore both cost-saving and effective, and calculation of net cost per OALY was not applicable.

In figure 1, the discounted healthcare cost savings associated with the NTC are plotted against the years since commence-

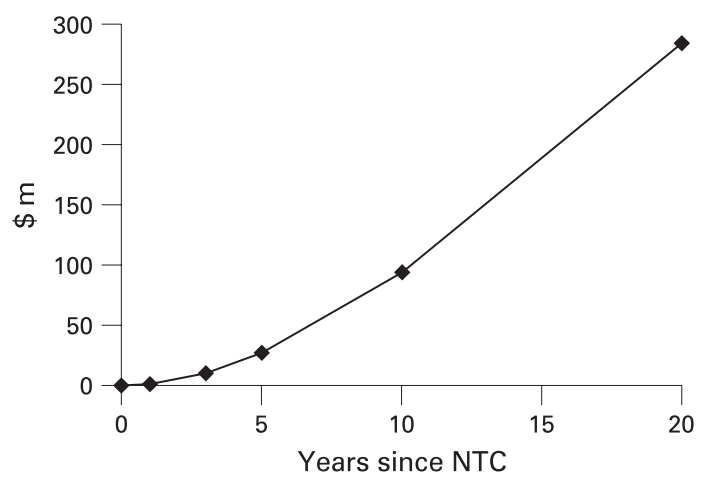

Figure 1 Predicted healthcare cost savings, discounted at 3\% per annum, plotted against years since the commencement of the National Tobacco Campaign (NTC). 
ment of the NTC. Figure 1 shows that by four years after the NTC, predicted healthcare cost savings exceeded the $\$ 10.1$ million cost of the programme.

The NTC's cost-effectiveness profile was essentially unchanged if only half the reduction in smoking prevalence observed during phase one was attributed to the NTC - that is, it was assumed there were 95000 rather than 190000 quitters. Under this scenario, the NTC was predicted to result in healthcare cost savings of $\$ 360.2$ million, and gains of 161500 life-years and 203500 OALYs for quitters over their remaining lifetime, so the programme was still unequivocally cost-saving as well as effective. Healthcare cost savings exceeded the cost of the programme cost within a five-year time horizon.

\section{DISCUSSION}

Our analysis found that the health benefits and healthcare cost savings consequential to the first phase of the NTC were far greater than previously estimated. Compared with Carter and Scollo's analysis, ${ }^{6}$ the OBM predicted that almost 60 -fold more deaths would be avoided, almost 100-fold more life-years would be saved and 30 -fold greater healthcare cost-savings would be achieved. This big difference is not surprising, because, as mentioned above, Carter and Scollo assessed the benefits of the NTC in only one hypothetical future year, whereas we assessed benefits over the remaining lifetime of quitters, censored at age 85 years.

Two other published cost-effectiveness analyses of massmedia anti-smoking campaigns also reported lower benefits than we found using the OBM. Ratcliffe et al ${ }^{16}$ estimated that a Scottish campaign, launched in 1992, cost between $£ 304$ and $£ 656$ per life-year saved, and Secker-Walker et al ${ }^{17}$ found that a mass-media programme conducted in two communities in the United States targeting adolescents cost $\$ 138$ (95\% CI 88 to 252) per life-year gained. However, neither of these analyses considered any healthcare cost savings associated with preventing smoking-attributable diseases. Other cost-effectiveness analyses of anti-smoking mass-media campaigns have estimated the cost per caller to quitlines in response to advertising, ${ }^{18}{ }^{19}$ or the cost per quitter. ${ }^{20}$

When considering proposals for funding new health programmes, governments now frequently consider data on costeffectiveness. ${ }^{21}$ In many instances an economic evaluation is mandatory. ${ }^{22}$ To facilitate consistent decisions, it is important that health economic evaluations are carried out using recognised, high-quality methodology. Our analysis of the cost-effectiveness of the NTC would arguably meet the high standard required for submissions to the Australian Pharmaceutical Benefits Advisory Committee (PBAC) seeking government subsidy of medicines. ${ }^{22}$ Our analytical model, the $\mathrm{OBM}$, reflects real-life risks, and is robust. In the technical paper describing its development, we reported that one-way sensitivity analyses varying model parameters by $10 \%$ resulted in only small changes (all less than 4\%) in predicted OALY gains and healthcare cost savings. ${ }^{7}$ However, although the OBM is a comprehensive model, it is still conservative. It underestimates the benefits of smoking cessation, as only the four most common smoking-associated diseases were considered when analysing cases of disease, OALYs and healthcare costs.

Our analysis did have some limitations. Both it and the previous analysis of the cost-effectiveness of the $\mathrm{NTC}^{6}$ assumed that all of the estimated decline in smoking prevalence in phase one was attributable to the NTC, and that the quitters would not regress. ${ }^{6}$ Although it is clearly unlikely that none of the quitters resumed smoking, the smoking prevalence reduction observed in phase one was sustained. Smoking prevalence was estimated to be $21.8 \%$ at the second household telephone follow-up in November 1998, 20.7\% at the third follow-up in 1999 and $20.4 \%$ at the final follow-up in November 2000. ${ }^{3}$ Antismoking advertising was much less intense over these periods.

Our attribution of the observed decline in smoking rates to the NTC is supported by two types of evidence. The first is the numerous analyses of smokers' knowledge, intentions and actions conducted as part of the NTC evaluation. ${ }^{3-5}$ These demonstrated that many smokers saw the advertisements, were prompted by the messages to think about quitting and either intended or tried to do so. For example, almost $90 \%$ of smokers recognised the advertisements, and half of those who had seen the campaign images said they were more likely to quit. ${ }^{23}$ Approximately $3.6 \%$ of adult Australian smokers called the quitline in the year after the NTC began, and over that period the weekly volume of quitline calls was strongly correlated with the amount of television advertising, measured in target audience rating points (TARPs). ${ }^{24}$

The second line of evidence for our assumption that the fall in smoking prevalence was the result of the campaign is the fact that only other controllable factor that is known to reduce the smoking rate was not applicable during the sixth-month phase one period. Wakefield and colleagues recently reported the results of a multivariate time series analysis, which showed that the only two interventions that significantly reduced smoking prevalence in Australia between 1995 and 2006 were exposure to anti-smoking media campaigns and increases in cigarette costliness (the ratio of average cigarette pack price to average weekly earnings). ${ }^{25}$ Between May and November 1997, there was no increase in cigarette taxes and the average retail price paid by Australian smokers increased by only $1.4 \%$ (Table 5 in paper by Scollo et $a^{26}$ ). International research ${ }^{27}$ suggests that for every $10 \%$ increase in cigarette prices, cigarette consumption falls by about $4 \%$, with around half of the fall due to quitting and half due to reduced cigarette consumption by smokers. The $1.4 \%$ increase in price over phase one of the NTC would therefore be predicted to have resulted in a $0.56 \%$ decrease in demand. Even if all of this reduction in demand was attributed to quitting, smoking prevalence would be predicted to decrease by only $0.13 \%$ (from $23.5 \%$ to $23.37 \%$ ). This represents only $9 \%$ of the actual prevalence reduction of $1.4 \%$ (from $23.5 \%$ to $22.1 \%$ ). So, in summary, cigarette price increases are the only factor other than the mass media campaign that could have had a substantial impact on smoking prevalence, and over the six-month period we analysed there was only a very small increase in the average cigarette price, the impact of which on prevalence was also very likely to be small.

Ten years have now passed since the first phase of the NTC was completed, and it is pertinent to ask what the impact has actually been. The beneficial impact on health is mostly likely to be first observed in reduced incidence and mortality of myocardial infarction and stroke. ${ }^{28}$ Between 1996 and 2005, the age-standardised incidence of major coronary events in Australia fell by 29\%, from 719 per 100000 to 511 per 100 000, and the corresponding death rate fell by $43 \%$ in men and $41 \%$ in women. ${ }^{29}$ The greater magnitude of the fall in mortality than incidence is likely to be due to better survival. Over the same period, age-standardised death rates for cerebrovascular disease (which is mainly stroke) fell by $37 \%$ for men and $35 \%$ for women. The prevalence of other risk factors for coronary heart and cerebrovascular disease may also have declined since the NTC began, but the most recent comprehensive survey data for the relevant risk factors (hypertension, elevated serum cholesterol, physical inactivity and obesity) are for the year 1999$2000 .^{29}$ It is reasonable to conclude that the reduction in 


\section{What this paper adds}

- The Australian National Tobacco Campaign (NTC) commenced in 1997 with an intensive mass media anti-smoking advertising campaign and coordinated support services for quitters. Phase one, between June and November 1997, cost around $\$ A 9$ million. A previous analysis grossly underestimated its cost-effectiveness, as benefits were assessed in only one future hypothetical year.

- This analysis assessed the cost-effectiveness of the NTC over the subsequent lifetime of quitters (censored at age 85 years) using a Markov simulation model. Outcomes included gains in quality-adjusted life-years (OALYs) and healthcare cost savings consequential to the reduced incidence of the four most common smoking-associated diseases-myocardial infarction, stroke, lung cancer and chronic obstructive pulmonary disease.

- Over the remaining lifetime of the 190000 quitters, the model predicted that there would be 55000 fewer deaths as a consequence of quitting, and a gain of over 400000 QALYs. Healthcare cost savings of around $\$ A 740$ million (discounted at $3 \%$ per year) were predicted. The NTC was therefore both cost saving and effective. The predicted benefits were 30 -fold to 100 -fold greater than previously estimated

- Countries that are party to the World Health Organization Framework Convention on Tobacco Control have committed to implement public awareness programmes on the health risks of smoking. This analysis should help them secure funding for such programmes.

smoking has contributed to these large declines in cardiovascular morbidity and mortality, and cerebrovascular mortality. For example, an Australian analysis of the $83 \%$ decline in coronary heart disease mortality during an earlier period, between 1968 and 2000, found that 16\% of the reduction in males was due to the decline in tobacco smoking. ${ }^{30}$

Over 150 countries have now ratified the World Health Organization Framework on Tobacco Control, ${ }^{31}$ and Article 12 of this treaty ${ }^{32}$ states that each party:

"shall promote and strengthen public awareness of tobacco control issues using all available communication tools, as appropriate. Towards this end, each Party shall adopt and implement effective legislative, executive, administrative or other measures to promote:

(a) broad access to effective and comprehensive educational and public awareness programs on the health risks including the addictive characteristics of tobacco consumption and exposure to tobacco smoke;

(b) public awareness about the health risks of tobacco consumption and exposure to tobacco smoke, and about the benefits of the cessation of tobacco use and tobacco-free lifestyles..."

In order to meet their treaty commitments, countries that have become party to the Framework Convention on Tobacco Control will therefore need to implement, or continue to support, massmedia anti-smoking campaigns, Accurate estimates of the efficiency of such campaigns are likely to be important in this context, as cost-effectiveness analyses of health care, health promotion and disease prevention programmes increasingly contribute to funding decisions and resource allocation. ${ }^{33}$ Our finding that an Australian mass-media anti-smoking programme was unequivocally costeffective should assist tobacco control advocates worldwide to secure funding for similar, ongoing programmes.
Funding: This project was supported by a grant from the Cancer Council Victoria, through funding from the Victorian Health Promotion Foundation. The funding body had no role in the design and conduct of the study, in the collection, analysis and interpretation of the data, or in the preparation, review or approval of the manuscript.

Competing interests: None.

\section{REFERENCES}

1. Hill D, Carroll T. Australia's national tobacco campaign. Tob Control 2003;12(suppl II):ii9-14.

2. Woodward A, Kawachi I. Tobacco control in Australia. Tob Control 2003:12(suppl II):ii1-2.

3. Australia's National Tobacco Campaign. Evaluation report volume three. http:// www.quitnow.info.au/internet/quitnow/publishing.nsf/content/ D2D1DC8EA1C5CB8BCA257475001ADB96/\$File/tobccamp3.pdf. Canberra: Australian Government Department of Health and Ageing, 2004.

4. Australia's National Tobacco Campaign. Evaluation report volume one. http:// www.quitnow.info.au/internet/quitnow/publishing.nsf/content/ D2D1DC8EA1C5CB8BCA257475001ADB96/\$File/tobccamp1.pdf. Canberra: Commonwealth Department of Health and Aged Care, 1999.

5. Australia's National Tobacco Campaign. Evaluation report volume two. http:// www.quitnow.info.au/internet/quitnow/publishing.nsf/content/ D2D1DC8EA1C5CB8BCA257475001ADB96/\$File/tobccamp2.pdf. Canberra: Commonwealth Department of Health and Aged Care, 2000.

6. Carter R, Scollo M. Economic evaluation of the national tobacco campaign. In: Hassard K, ed. Australia's national tobacco campaign. Evaluation report volume two. http://www.quitnow.info.au/internet/quitnow/publishing.nsf/content/ D2D1DC8EA1C5CB8BCA257475001ADB96/\$File/tobccamp2.pdf. Canberra: Commonwealth Department of Health and Aged Care, 2000:201-38.

7. Hurley SF, Matthews JP. The quit benefits model: a Markov model for assessing the health benefits and healthcare cost savings of quitting smoking. Cost Eff Resourc Alloc 2007:5:2-22.

8. TreeAge Software Inc. TreeAge Pro 2007 User's Manual. Williamstown, MA: TreeAge Software Inc, 2007.

9. Chapman KR, Bourbeau J, Rance L. The burden of COPD in Canada: results from the Confronting COPD. Resp Med 2003;97:S23-31.

10. Tengs TO, Lin TH. A meta-analysis of quality-of-life estimates for stroke. Pharmacoeconomics 2003;21:191-200.

11. Tufts-New England Medical Center. The CEA Registry. Institute for Clinical Research and Health Policy Studies, 2006. (Accessed 14 Oct 2005, at http://www. tufts-nemc.org/cearegistry/data.html.)

12. Cost-effectiveness in health and medicine. New York: Oxford University Press, 1996

13. Peto R, Darby S, Deo H, et al. Smoking, smoking cessation, and lung cancer in the UK since 1950: combination of national statistics with two case-control studies. BMJ 2000;321:323-9.

14. Wakefield M, Freeman J, Boulter J. Changes associated with the national tobacco campaign. Pre and post campaign surveys compared. In: Hassard K, ed. Australia's national tobacco campaign. Evaluation report volume one. http://www.quitnow.info. au/internet/quitnow/publishing.nsf/content/ D2D1DC8EA1C5CB8BCA257475001ADB96/\$File/tobccamp1.pdf. Canberra: Commonwealth Department of Health and Aged Care, 1999:24-82.

15. Australian Bureau of Statistics. Consumer price index. Australia: Australian Bureau of Statistics, 2006. (Accessed 1 Dec 2006, at http://www.abs.gov.au/ Ausstats/abs@.nsf/lookupresponses/ 01893cb232a02c6aca2570a5008054ef?opendocument.

16. Ratcliffe J, Cairns J, Platt S. Cost effectiveness of a mass media-led anti-smoking campaign in Scotland. Tob Control 1997;6:104-10.

17. Secker-Walker RH, Worden JK, Holland RR, et al. A mass media programme to prevent smoking among adolescents: costs and cost effectiveness. Tob Control 1997:6:207-12

18. Farrelly MC, Hussin A, Bauer UE. Effectiveness and cost effectiveness of television radio and print advertisements in promoting the New York smokers' quitline. Tob Control 2007;:16(suppl 1):i21-3.

19. Mosbaek CH, Austin DF, Stark MJ, et al. The association between advertising and calls to a tobacco quitline. Tob Control 2007;16(suppl 1):i24-9.

20. Mudde AN, De VH. The reach and effectiveness of a national mass media-led smoking cessation campaign in The Netherlands. Am J Public Health 1999:89:346-50.

21. Pearson SD, Rawlins MD. Quality, innovation, and value for money. NICE and the British National Health Service. JAMA 2005;294:2618-22.

22. Commonwealth Department of Health and Ageing. Guidelines for the pharmaceutical industry on preparation of submissions to the Pharmaceutical Benefits Advisory Committee. Canberra: Commonwealth of Australia, 2002.

23. Wakefield M, Freeman J, Donovan R. Recall and response of smokers and recent quitters to the Australian National Tobacco Campaign. Tob Control 2003;12(suppl II):ii15-22.

24. Miller CL, Wakefield M, Roberts L. Uptake and effectiveness of the Australian telephone Quitline service in the context of a mass media campaign. Tob Control 2003;12(suppl II):ii53-8.

25. Wakefield MA, Durkin S, Spittal MJ, et al. Impact of tobacco control policies and mass media campaigns on monthly adult smoking prevalence. Am J Public Health 2008:98:1443-50. 
26. Scollo M, Younie S, Wakefield M, et al. Impact of tobacco tax reforms on tobacco prices and tobacco use in Australia. Tob Control 2003;12(suppl II):ii59-66.

27. Centers for Disease Control and Prevention. Response to increases in cigarette prices by race/ethnicity, income and age groups_-US, 1976-1993. Morb Morty Wkly Rep 1998;47

28. Hurley SF. The short-term impact of smoking cessation on myocardial infarction and stroke hospitalisations and costs in Australia. Med J Aust 2005:183:13-17.

29. Australian Institute of Health and Welfare. Australia's health 2008. Canberra: AlHW, 2008.

30. Taylor R, Dobson A, Mirzaei M. Contribution of changes in risk factors to the decline of coronary heart disease mortality in Australia over three decades. Eur $\mathrm{J}$ Cardiovasc Prev Rehabil 2006;13:760-8.

31. Tobacco Free Initiative. Updated status of the WHO Framework Convention on Tobacco Control. World Health Organization, 2008. (Accessed 14 Jan 2008, at http:// www.who.int/tobacco/framework/countrylist/en/index.html.)

32. World Health Organization. WHO Framework Convention on Tobacco Control. Geneva: WHO, 2005.

33. Detsky AS, Laupacis A. Relevance of cost-effectiveness analysis to clinicians and policy makers. JAMA 2007;298:221-4.

34. Australian Institute of Health and Welfare. National Cancer Statistics Clearing House, 2006. (Accessed 13 July 2005, at http://www.aihw.gov.au/cancer/ datacubes/index.cfm.)

35. Peto R, Lopez AD, Boreham J, et al. Mortality from tobacco in developed countries: indirect estimation from national vital statistics. Lancet 2005;339:1268-78.

36. Ko CY, Maggard M, Livingston EH. Evaluating health utility in patients with melanoma, breast cancer, colon cancer, and lung cancer: a nationwide, populationbased assessment. J Surg Res 2003;114:1-5

37. Trippoli S, Vaiani M, Lucioni C, et al. Quality of life and utility in patients with nonsmall cell lung cancer. Quality-of-life Study Group of the Master 2 Project in Pharmacoeconomics. Pharmacoeconomics 2001;19:855-63.

38. Rosenthal M, Webster PJ, Gebski VJ, et al. The cost of treating small cell lung cancer. Med J Aust 1992:156:605-10.
39. Oliver E, Killen J, Kiebert G, et al. Treatment pathways, resource use and costs in the management of small cell lung cancer. Thorax 2001;56:785-90.

40. Australian Institute of Health and Welfare. GRIM (General Record of Incidence of Mortality) Books. Canberra: AlHW, 2005.

41. National Hospital Morbidity Database. Australian Institute of Health and Welfare, 2006. (Accessed 14 0ct 2005, at http://www.aihw.gov.au/hospitals/datacubes/ datacube pdx.cfm\#pdc.)

42. English $\overline{\mathbf{D}}$, Holman CD, Milne E, et al. The quantification of drug caused morbidity and mortality in Australia 1995. Canberra: Department of Human Services and Health, 1995.

43. Australian Bureau of Statistics. National Health Survey-summary of results, Canberra: Australian Bureau of Statistics, 2002.

44. Barendregt JJ, Van Oortmarssen GJ, Vos T, et al. A generic model for the assessment of disease epidemiology: the computational basis of DisMod II. Population Health Metrics 2003:1:4

45. Thrift AG, Dewey HM, Macdonell RAL, et al. Stroke Incidence on the East Coast of Australia. The North East Melbourne Stroke Incidence Study (NEMESIS). Stroke 2000:31:2087-92

46. Hardie K, Jamrozik K, Hankey G, et al. Trends in five-year survival and risk of recurrent stroke after first-ever stroke in the Perth Community Stroke Study. Cerebrovascular Diseases 2005;19:179-85.

47. Hardie K, Hankey GJ, Jamrozik K, et al. Ten-year survival after first-ever stroke in the Perth Community Stroke Study. Stroke 2003;34:1842-6.

48. Dewey H, Thrift AG, Mihalopoulos C, et al. Lifetime cost of stroke subtypes in Australia. Findings from the North East Melbourne Stroke Incidence Study (NEMESIS). Stroke 2003:34:2502-7.

49. Organisation for Economic Co-operation and Development. Purchasing power parities (PPPs) for OECD countries 1980-2004. 2006. (Accessed 14 Oct 2005, at http://www.oecd.org/LongAbstract/ 0,2546,en_2825_495691_1876126_1_1_1_1,00.html.)

50. Taylor $\mathbf{D H}$, Hasselbad V, Henley J, et al. Benefits of smoking cessation for longevity. Am J Public Health 2002:92:990-6.

\section{The lighter side}

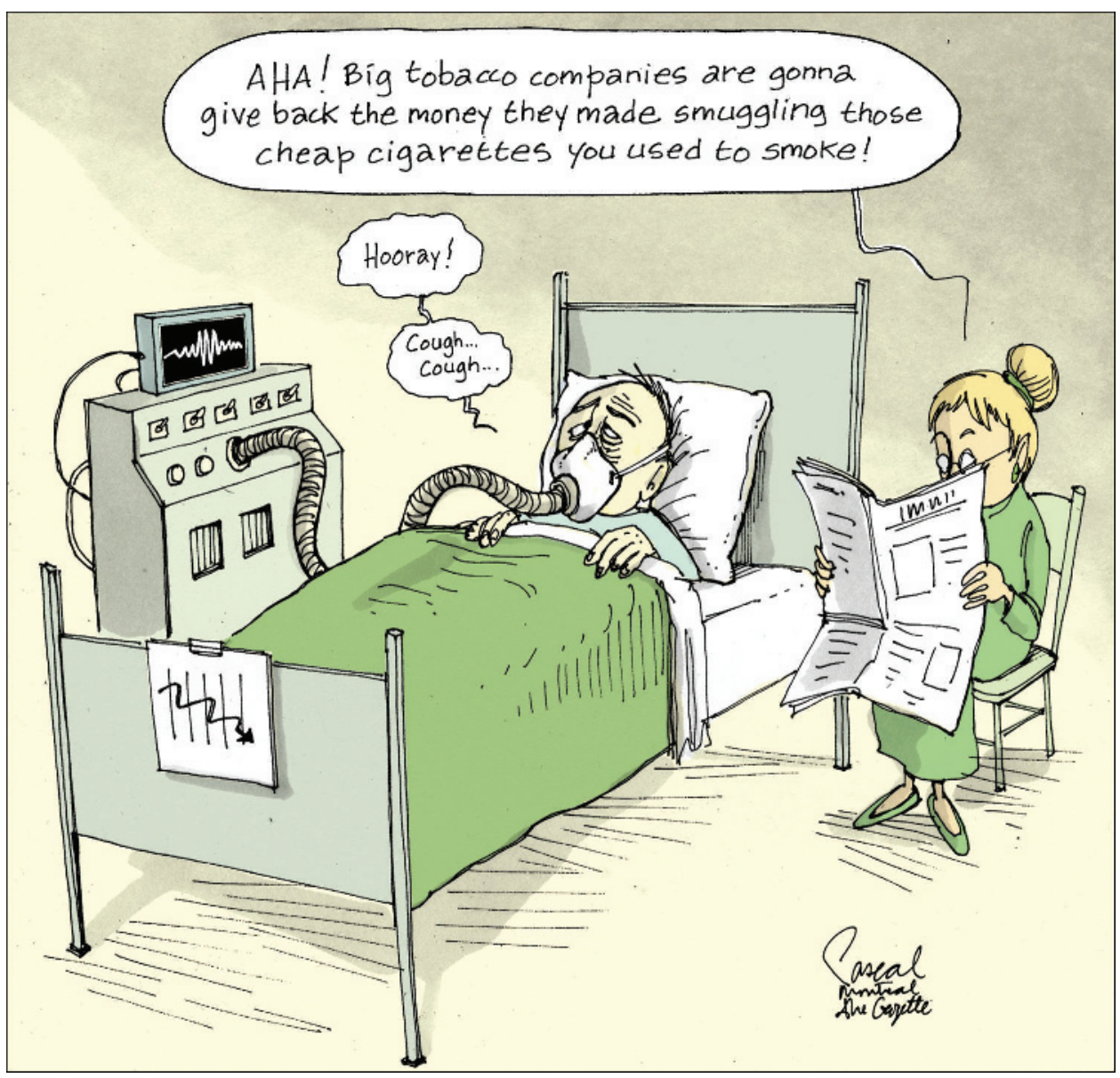

(c) Pascal, The Gazette, Montreal, 2008. 